\title{
Polygonal Nodule
}

National Cancer Institute

\section{Source}

National Cancer Institute. Polygonal Nodule. NCI Thesaurus. Code C157676.

A nodule shape that is a two dimensional with 3 or more straight sides that do not cross

and is a closed shape. Examples of polygons would include triang les, squares, rectangles,

hexagons, and octagons. Polygonal nodules are commonly delimited by interlobular

septal margins and are a feature of intrapulmonary lymph nodes or possibly

bronchiolar/arteriolar disease. 